\title{
Direct perception in context: radical empiricist reflections on the medium
}

\author{
Ludger van Dijk ${ }^{1}\left[0 \cdot\right.$ Julian Kiverstein ${ }^{2}$
}

Received: 21 June 2019 / Accepted: 6 February 2020 / Published online: 19 February 2020

(c) The Author(s) 2020

\begin{abstract}
Radical empiricists at the turn of the twentieth century described organisms as experiencing the relations they maintain with their surroundings prior to any analytic separation from their environment. They notably avoided separating perception of the material environment from social life. This perspective on perceptual experience was to prove the inspiration for Gibson's ecological approach to perceptual psychology. Gibson provided a theory of how the direct perception of the organism-environment relation is possible. Central to his account was the notion of a medium for direct perception. However Gibson provided two mutually inconsistent accounts of the medium leading to problems for his radical empiricism. We develop an account of the medium that does justice to ecological psychology's radical empiricist roots. To complement this account of the medium we detail a usage-based account of information. Together they allow us to propose a novel radical empiricist view of direct perception. We then return to the notion of medium and expand it to include sociomaterial practices. We show how direct perception happens in the midst of social life, and is made possible by an active achieving and maintaining of a pragmatic relation with the environment.
\end{abstract}

Keywords Ecological psychology $\cdot$ Information $\cdot$ Medium $\cdot$ Perception $\cdot$ Practices $\cdot$ Radical empiricism

Life is in the transition as much as in the terms connected; often indeed, it seems to be there more emphatically, as if our spurts and sallies forward were the real firing line of the battle (James 1912, p. 45)

$凶 \quad$ Ludger van Dijk

Ludger.vanDijk@uantwerpen.be

1 Department of Philosophy, Centre for Philosophical Psychology, University of Antwerp, Rodestraat 14, 2000 Antwerp, Belgium

2 Department of Psychiatry and Amsterdam Brain and Cognition, Academical Medical Center, University of Amsterdam, Amsterdam, The Netherlands 


\section{Introduction}

In the radical empiricist philosophy of the early twentieth century perception is understood as a relational, world-involving activity (James 1912). Perceivers actively adapt to the environment and their experiences grow out of this process of active adaptation. The radical empiricist approach to direct perception argues that the experienced relation and the relata of organism and environment take shape together in activity, as William James suggests in the epigraph to our paper. Harry Heft convincingly showed in his book 'Ecological psychology in context' (2001; see also Heft 2017) that the legacy of radical empiricism was continued by James Gibson in his theory of direct perception (Gibson 1966, 1979). Gibson showed how perceiving is achieved in action, it is an actively "keeping-in-touch with the world" (Gibson 1979, p. 239). In doing so, organisms can directly perceive the relation they establish in terms of what the environment affords them to do. Our aim in what follows is to further develop the radical empiricist perspective on direct perception that inspires ecological psychology.

A desideratum for a radical empiricist account is that it accounts for perception in the context of daily life. Human perception, from an infant orienting to the voice of her mother to an adult set up to perform a color discrimination task in a psychology lab, is steeped in social life. Perceptual psychology (including ecological psychology) has, by and large, aimed to isolate a "primitive" perceptual process, such as seeing an object's color or surfaces, from its social context. In the radical empiricist account we develop we show how this separation of a primitive perceptual process from its social context is a mistake (Heft 2007). Social life, being open-ended and prone to change, is not a later addition to a bedrock reality that perception aims to acquaint us with. A radical empiricist must take direct perception to be relational whether the relations are socially constituted or not.

There is however an unresolved tension in Gibson's work that we will argue obstructs the attempt to develop direct perception in this radical empiricist direction for ecological psychology. This tension manifests in different ways, as has been famously noted by Alan Costall (see Costall 1984; Costall and Still 1989). The tension relates to whether the environment should be understood as made up of ready-made structure, or whether activity always has a constitutive role to play in structuring the environment. It has consequences for thinking about the role of social life, language, and the commitment to realism in an ecological account of perception (Heft 1989; 2017; Ingold 2011; Costall 1995; Turvey 1992; Rietveld and Kiverstein 2014; Vaz 2015; Van Dijk and Myin 2018; Baggs and Chemero 2018; Heras-Escribano 2019). This tension, we'll show, also comes into sharp relief in Gibson's notion of the medium.

The introduction of the medium was a pivotal move in the ecological theory of direct perception. It allowed for a rich conception of stimulation, counteracting the still dominant idea in perceptual psychology of stimulation as being either ambiguous or too impoverished to specify its source. Gibson's writings however contain two accounts of the medium one of which leads to a view of direct perception at odds with radical empiricism. In the first view the medium is ready-made, and furnishes the subsequent possibility for keeping information available. Air for instance transmits light, odours and sound-waves, interacting with the substances in such a 
way as to convey information to the mobile animal. The "triad" of substances, surfaces and medium exist prior to the activities of organisms. We will call this the "ready-made" view. On the second view, the medium is defined relative to the activities that an organism develops. Air is the medium for locomotion, as it allows for unhindered movement while a wall is a 'substance' that does not allow for movement (Gibson 1966, p. 14, 1979, p. 19). The triad of substance, surfaces and medium take form through the organism's activity, and does not have a fixed determinate reality prior to the organism's activity. We will call this the activity-related view.

The two accounts of the medium are mutually exclusive. The ready-made view takes the medium to be there prior to activity, keeping the information available for the direct perception of the environment. The activity-related view takes the medium, surfaces and substance to form through the organism's activity. The medium however cannot be both ready-made, and also form in the organism's activities. We argue in favour of the activity-related view of the medium. The ready-made view leads to a separation of perception of an already existing environment from activities unfolding in social life. As a consequence, it has proven difficult to find a place for social life in human perception (Costall 1995; Heft 2007, 2017). Through developing an activityrelated view of the medium we will arrive at a view of direct perception that avoids making such a separation. The activity-related view of the medium readily allows a place for sociomaterial practices in direct perception.

However, one might think direct perception depends on the availability of information for making contact with the surroundings. So if there is no medium to contain information prior to activity, have we not deprived ecological psychology of their account of direct perception? To escape this problem we first propose a usage-based account of information, drawing upon earlier work by Withagen and Van der Kamp (2010) who were inspired by Oyama (2000). We argue that direct perception should be understood in processual and pragmatic terms (Van Dijk and Myin 2018). The perceptual relation that an organism achieves in its environment is a process taking shape over time as the relata of organism and environment form. It is by actively establishing the relation to its surrounds that the organism perceives what the environment affords. Direct perception is secured by thinking of the perceptual relation as open-ended, achieved and maintained in action. The usage-based account of information follows this processual and pragmatic understanding of direct perception. We go on to show how given this usage-based account of information, the activity-related view of the medium allows for an expanded notion of the environment to include sociomaterial practices.

Our paper comprises five sections. In Sect. 2 we describe the two views of the medium that can be found in Gibson's writings. Section 3 develops a usage-based account of information. We put this account of information to work in Sect. 4 to propose a radical empiricist view of direct perception. In Sect. 5 we describe how the activity-related view of the medium can expand to include sociomaterial practices. We end in Sect. 6 by arguing how the medium of practice extends the radical empiricist view of direct perception to account for a wider range of social phenomena than the ecological approach currently allows. 


\section{The medium for direct perception}

Prior to his introduction of a medium for perception, Gibson's theory of perception was based on the dynamical stimulation of the retina (Gibson 1950). However his organism-relative notion of stimulus left Gibson feeling that he had insufficiently accounted for individual organisms perceiving the same, shared, environment (Heft 2001). Moreover, although his conception of (ordinal) stimulation was dynamic, stimulation continued to be passively imposed. Gibson felt such a view of stimulation remained too impoverished to account for the perception of the richness and multiplicity of the ecological environment (see Gibson 1967; Reed 1988).

To overcome such problems, Gibson's borrowed the notion of the medium from his colleague and friend Fritz Heider (Heft 2001). Heider asked how perception of distal objects could be made possible by physical energy, such as light rays or soundwaves. To this end he scrutinized the differences between "thing and medium" (Heider 1959, originally published in 1926). Things are relatively solid, and resist deformation under the influence of external forces. For instance, when sound hits a wall, the wall will either deflect or absorb most of the energy in the process, but the structure of the wall is not (significantly) transformed by the sound. By contrast, media, such as air or water (ibid., p. 14), are much more loosely organized and respond very differently to sound or light. This flexible organization allows a medium to take over the structure of external energy and to retain and transmit such structure (e.g. sonic or optical structure) without much deformation. It thus allows for light rays to "mediate to us everything that is important for our behavior" (ibid., p. 28).

For Heider the medium of air allowed the structure of things to be transmitted without deformation to the eye by light rays, these rays are the "messengers from the object and represent it" (ibid., pp. 6-7). Notice that for Heider light carries content about, it represents, the objects that are its source. While highly influenced by Heider's analysis, Gibson proposed a different view of light (and of energy more generally). Gibson argued that light, at the ecological scale, was ambient in the sense of surrounding the mobile animal. It did not travel, and it was therefore not mediating perception. Ambient light was the result of illumination, while radiating light was the cause of it (Gibson 1979, p. 48 ff.). As radiant light reverberated and scattered off environmental structure, it became ambient and filled the medium. Air was then a medium, in part, because it contained ambient light (Gibson 1966, 1979). Following Heider, Gibson viewed the medium as allowing the patterns of ambient energy, such as light, to preserve the structure of the environment. By retaining the correspondences between surfaces and ambient patterns, these patterns could specify their environmental source. Ambient patterns were therefore potential stimulation, or information, for an active organism.

The ready-made view of the medium, like Heider's view, understands the triad of medium, substances and surfaces in terms of their physics. Each element of the triad has its own determinate and fixed reality prior to any organism encountering them. With the triad ready-made, the correspondences holding between its constituent elements likewise pre-exists. Direct perception is thus made possible by the information the medium keeps available. The organism is brought into contact in perception with a ready-made environment through the information the medium furnishes. But this view of direct perception is premised on the relata of organism and environment pre-existing 
the relation that forms out of them. Such a separation of organism from a pre-existing environment is in tension with radical empiricism which holds a view of perception, as relational process in which its relata, the organism and environment, are continuously taking shape over time. Fortunately, there is another view of the medium in Gibson's writings that is more in keeping with a radical empiricist perspective we're developing.

\subsection{The medium-for-action}

Gibson emphasized that organisms are surrounded by a "flowing sea" of ambient energy (e.g. Gibson 1979, p. 57 ff.), which also includes acoustical, chemical and mechanical energy. All this energy is patterned, it forms an ambient array. Relative to particular organisms, some of the energy is condensed such that it forms substances (water to a pond skater), and some forms a medium (air to a human, water to a fish). A limited range of the reverberating flux of energy is moreover patterned such that perceptual systems can learn to be sensitive to that energy (e.g. magnetic fields to birds, light, sound odor, and so on to humans).

From his earliest use of the term, Gibson introduces the medium not only to contain ambient patterns and to "permit the flow of information" (Gibson 1966, p. 14, emphasis original), but also in relation to activity. We will suggest this leads to a second view of the medium we have called the "activity-related" view. Air, for example, was a "medium for terrestrial locomotion" because terrestrial animals can move through it unobstructed (ibid.). Water is not merely the container of ambient patterns, but it is walkable for pond skaters. Gibson talks of the medium to denote the surrounding substrate that allows an animal to act, coordinating its activities to its surroundings.

In his later work, Gibson discusses the medium in relation to a whole "triad of medium, substances and surfaces" (Gibson 1979, p. 22). This triad is distinguished by Gibson relative to the activity of an animal. Substances are contrasted with the medium in that they "do not permit the motion of bodies" and are "more or less resistant to deformation" (ibid., p. 19, emphasis original). Surfaces only form where substances and medium meet-they are the interface between them (ibid., p. 16). Gibson sometimes characterizes surfaces as "separating" substance from medium. From the outset all three aspects of the "triad" are defined relative to one another, but crucially also to the activity under consideration. It is locomotion that differentiates air as a medium; the sand resisting the weight of our feet as we stand that differentiates it as substance. It is out of our activities that the interface between medium and substance takes form as a surface that we perceive as affording support (see also Ingold 2011, chapter 8).

Gibson was explicit in defining the environment as the triad of substances, surfaces and medium relative to the way of life of "a kind of animal" (Gibson 1979, p. 21). He considered the environment at this grain of analysis as a description of a "very general" kind (Gibson 1979, p. 36). In addition, he aimed for "more particular descriptions," differentiating substances on the basis of the use for a particular species, rather than a class of species (terrestrial animals). A human animal is for example not only terrestrial but also a "pedestrian" (ibid.). Thus the environment differentiates further into paths, steps, shelters, fire, tools and other animals - each affording a host of activities. 
Gibson thus transitions from thinking of the medium as merely permitting movement, understood in terms of the change of position over time, to instead thinking of the medium in relation to the activities it enables. As his descriptions of the environment become further differentiated, he arrives not only at a medium, substances and surfaces defined in relation to a kind of animal, but to the environment in relation to what a particular animal is doing.

Consider in this light Gibson's discussion of the status of water (ibid., p 38). He notes that water is usually not a medium for a human, but it can become a medium for those who are able to swim. For those that can swim water affords actions such as diving, and seeing what lies beneath the water while diving. Water will however remain a substance for those who are merely rinsing out their hair, or for those who cannot swim. While swimming, water can quickly turn from being a medium to being a substance with potentially dramatic consequences. When stamina runs out and coordinated skills give way, the water forming a medium for swimming can quickly (re)turn to a substance, and begin to afford little more than drowning.

What this foray into the aquatic world of terrestrial animals shows is that defined in terms of action, the triad of medium, substances and surfaces does not come readymade. The medium, substances and surfaces are differentiated in an animal's activities. We see this vividly in the example of swimming: skillful coordination is what allows water to be the medium through which an otherwise terrestrial animal can move. It is also because of such skills that we might make use of ambient light that reverberates throughout the water to see what lies under water. When coordination gives way, our muscles give in or the waves get too high, coordination fails, and the medium can no longer be sustained. The coordination to ambient patterning is lost or becomes unavailable to the struggling swimmer. Conversely, anyone who has ever snorkeled will recall how it takes some time to stop drowning, relax, breathe normally and find the underwater world opening up to you.

The two views of the medium we've outlined in this section do not sit well with each other. ${ }^{1}$ Water, on an activity related view, fluidly turns form substance into medium, while on the ready-made view this transition makes no sense. Water is either medium or substance. It cannot switch from being one to the other.

The two views lead to different views of how an animal perceives the environment. The ready-made view leads to a view of direct perception in which the medium contains information that allows the perceiver to get into contact with its surrounds. On the ready-made view this is something the medium can do by virtue of preserving the

\footnotetext{
${ }^{1}$ It might be thought that the distinctions Baggs and Chemero (2018) make between the "habitat" and the "Umwelt" shows that there is no inconsistency in Gibson's treatment of the medium. What we are calling the activity-related view of the medium can be understood as falling squarely within the Umwelt, which is defined in relation to individual perceiving animals. The ready-made view of the medium can in turn be thought of as forming a part of the organism's habitat that exists independently of any individual animal, but is defined relative to an ideal member of a species instead (cf. Segundo-Ortin et al. 2019). We thank an anonymous reviewer for making this suggestion. While Baggs and Chemero are right to highlight this important conceptual distinction, we suggest it remains an important project to show how these two conceptions of the environment can be brought back together once they have been distinguished (see Kiverstein et al. 2019). It makes sense to distinguish habit from Umwelt analytically, and for experimental purposes, but it doesn't follow that an account isn't therefore owed of how to think about the continuity of the two environments before an analytic separation of them has been made. This paper can be read as attempt at doing so (see also Kiverstein et al. 2019).
} 
correspondences connecting ambient patterns with the surfaces of the environment. This preservation guarantees that the ambient patterns the medium contains specify the environment. The medium thus pre-exists the activity required to discover the information it already contains. On the activity-related view a medium takes shape in action and therefore cannot be a container of ready-made, pre-given information. But if the medium doesn't contain information prior to activity, how then is direct perception possible? In the next section we show how it follows from the activityrelated view of the medium that information only exists in action. Ambient patterns can be more or less useful, allowing an information-relation to take shape in which an active organism directly perceives its surrounds.

\section{A usage-based account of information}

We've seen how the ready-made view of the medium is in tension with radical empiricism because it takes the environment to exist prior to the organism's activities. The medium in this view is understood as making available information for the direct perception of such a pre-existing environment. The medium makes information available by preserving the correspondences that hold between the ambient structure and the layout of surfaces and therefore contains ambient structure as information. Information is considered to be intrinsically "about" the environment by virtue of these "lawful" correspondences (e.g. Michaels and Carello 1981; Turvey 1990). Thus information is intrinsically about something (its source) independent of any user of such information. Indeed, the availability of information that specifies its source in advance of acting is taken to be a sine qua non in orthodox ecological psychology (Turvey and Shaw 1999; Turvey 2019).

The orthodoxy in ecological psychology has been criticized for leading to an unduly restrictive theory of direct perception. Withagen and Chemero (2009) argued for allowing variation in perceptual sensitivities and "suboptimalities" in perception across organisms which would bring direct perception in line with evolutionary theory. One line of response to this objection from evolutionary theory attempts to extend the orthodox approach to information to include any ambient pattern, including those that are captured only through statistical relations to environmental events, such as by "relation[s] of convention" (Gibson 1966, p. 235). The lawfully specifying variety of information would turn out to be only a special case (Chemero 2009; Bruineberg et al. 2018). We will however follow an alternative second line of response that calls into question the existence of information prior to its active use.

Oyama (2000) argued that genes do not carry information that programmes for the form an organism develops. Genes are one among a whole constellation of factors that together shape a complex developmental process (Oyama 2000). Genes only get to contribute information for development through participating in this process. Oyama's important point also applies to the concept of information as it is employed in ecological psychology. What information is for is "co-determined" by the patterns in the ambient array and "by the perceptual process it is participating in" (Withagen and Van der Kamp 2010, p. 158). Lawful correspondences can indeed hold between ambient patterns of energy and the layout of the environment, but these correspondences do 
not by themselves suffice to specify the meaningful environment of an organism (Van Dijk et al. 2015; see Hutto and Myin 2013). What matters for specification is how the resulting patterns of light, sound and all the rest, are used, how they contribute to an organism maintaining and remaining adapted to a dynamic environment, each time anew.

Recall that on the activity-related view of the medium, surfaces, that need to correspond to the patterned ambient array, form out of medium and substances. But neither medium nor substances have a determined and fixed reality prior to the unfolding activities themselves. Thus the significance of the correspondences between surfaces and the ambient energy is not given a priori by something fixed on either side of this organism-environment relation but only in the organism-environment relation. The ground, for instance, becomes a textured surface in the context of walking. The ground is specified as such, as walkable, by the flow of ambient patterns of light forming in and along the medium that is made available as we walk. It is in the context of such ongoing activity that ambient patterns can be explored for their use.

If lawful correspondences between ambient patterns and surfaces do not have a priori significance for a perceiver, then how do ambient patterns come to be of informational significance? Ambient patterns and their relations within and across various energy types are abundant. Ambient patterns moreover envelop the animal over multiple spatiotemporal scales as it moves through its environment. Ambient patterning unique to the organism-environment relation were discussed by Gibson as "perspective structure." Such actively generated patterning varies over time: it "changes with every displacement of the point of observation" (Gibson 1979, p. 73). Think again of diving into water: as one dives forward, the surrounding optical patterning continuously flows backwards. Given the usefulness of optic flow it is not surprising that organisms have been shown to be highly sensitive to such patterning (e.g. Lee and Reddish 1981; Warren et al. 2001). We suggest to think of lawful correspondences and perspective structure as reciprocally related in ambient patterning. Both lawful correspondence and perspective structure concurrently take shape in the activity that gives rise to differentiation of medium, substances and surfaces. It is in the context of activity (e.g. diving), and the perspective structure it generates (e.g. optic flow), that lawful correspondence can be informationally significant (cf. Gibson 1979. p. 76; 122).

Ecological psychologists have tended to focus on structure-preserving correspondences between ambient patterns and surfaces carried in the medium. We suggest this presupposes the transformative process of acting in which substances, medium and their various ways of corresponding come into being. The existence of correspondences (between ambient patterns and surfaces) are necessary but not sufficient for information. For such correspondences to provide information for an animal, the triad must have already been taking shape in activity. Only then can correspondences be taken up in coordination and used by the animal to make a difference to its practical activity (Bateson 1972; Oyama 2000; see Johnston 1997; Van Dijk et al. 2015; Vaz 2015; Withagen and van der Kamp 2010). On the radical empiricist view we're developing in this paper, coordination consists in the bodily adjustments of achieving and maintaining an organism-environment fit. An example of coordination is acting in such a way that water allows one to swim in it and perceive under water. It is relative 
to this ongoing coordination that (lawful) correspondences take shape and get their use.

Thus taking activity as primary has the consequence that information is not strictly contained in any physical substrate, such as patterns in light or sound. Nor is it confined to any structural correspondence between surfaces and ambient patterns: information is a relation spanning the whole actively maintained organism-environment system. Information is not something that the medium can contain but rather a relation maintained along the organism-environment system (Johnston 1997). Ambient patterns of energy are necessary for establishing such an information-relation, spanning the entire organism-environment system. But it is only when these ambient patterns are used by an organism in its activities that they take part in the information-relation as a whole. They are, in other words, not just a difference, but in their use ambient patterns become a difference that makes a difference (Bateson 1972). We will therefore talk of an 'information-relation' that the medium enables through an animal's activities. ${ }^{2}$

\subsection{Specification in action}

Thinking of information as a relation taking shape in activity is a reversal of the orthodox view of direct perception in ecological psychology. We don't start from two pre-given relata: an organism and an environment. Our starting point is the forming of the pragmatic relational process in which organism and environment, medium and surfaces, concurrently take shape. On the orthodox view, information is said to specify its source: lawful correspondences pre-condition use by fixing the significance of ambient patterns. We argue by contrast that it is the use of patterns that establishes their informational significance. Information is then not merely instrumental, contained in a medium that animals perceive through. Information is a relation that comes into being in situated activity. We perceive in ambient energy, along an information-relation. Information is constituted in use. It is along this unfolding information-relation that the skilled animal perceives its affording environment.

The usage-based account of information, and its notion of "specification," does justice to radical empiricism in two important ways. First, specification is thought of as a process in which the organism-environment relation forms. On this reading, in activity one achieves and maintains an organism-environment fit. Success in coordination-in achieving and maintaining fit with the environment—is determining the significance

\footnotetext{
${ }^{2}$ Several contemporary views also hold a relational notion of information (Segundo-Ortin et al. 2019; Golonka and Wilson 2019). Segundo-Ortin and colleagues (2019) note that there are important differences between the usage-based account of information we defend, and the relational account of information they propose. For them, specification is understood in relation to a kind of animal, but does not depend on (an ongoing history of) actually unfolding activity of any individual (ibid., p. 1011; cf. Baggs and Chemero 2018). We can thus make a distinction between a conceptual and a temporal understanding of the environment in relation to an organism or species. On the former view the relation is thought of by analogy with the logical structure of conceptual relations like "taller-than" (cf. Chemero 2009) that hold independently of the activity of the relata involved. For us, both organism and environment, and indeed species, take form as their relations unfold in process-a process that is perpetually unfinished. What sets our proposal apart from other relational views of information is the temporal unfolding of the relations we describe. Information-relations, on our view, are open-ended and constitutively involve the activity of achieving them.
} 
that ambient patterns have in the unfolding information-relation. This success is however only completely determined in retrospect, after the activity has unfolded (Shotter 1983; Schatzki 2012; Van Dijk and Rietveld 2018). To think of ambient patterns, or its lawful correspondence, as sufficient to specify the environment is to reify "eventual functions into antecedent existence" (Dewey 1958, p. 29). It takes a possible outcome of a coordinative process, the organism-environment fit, for its pre-existing source (Van Dijk 2016). By contrast, on the radical empiricist view specification is not an all or nothing state, fixed by lawful correspondences ahead of action. Rather specification is a process, achieved in activity over time.

An important consequence of this processual understanding of specification is that we have no need for a distinction between specifying and non-specifying information, between relations of "convention" or "projection" (Gibson 1966, p. 235). Both correspondences given by convention and projection are discernable in the use we can get from them, they do not prescribe such use. Thus there is no need to make an ontological separation between natural pre-given forms of information and information that owes its existence to social life. Nor is there on our view a need to introduce non-specifying information to account for cases in which the significance of ambient patterns seems ambiguous or indeterminate (cf. Withagen and Chemero 2009). Determinacy in our view is achieved in acting; the process of specifying takes form over the course of ongoing situated activity. Specification, as we'll be using the term, is not the source of situated activity but is the unfolding outcome of such activity (Shotter 1983; Van Dijk and Rietveld 2018).

The second way in which our notion of specification, does justice to radical empiricism, is that on a usage-based account, what comes to be specified over time is a pragmatic organism-environment relation. Our notion of specification thus explicitly adheres to the commitments of ecological psychology that information is not about perceiving the world correctly or truthfully (accurately, veridically), but about being more or less adapted to one's surrounds (Mace 2002). The normativity of doing better or worse is a pragmatic normativity that belongs to an organism's activity. This distinction between doing better or worse we understand in terms of coordination - that is the achieving and maintaining of an organism-environment fit. If one achieves coordination and thus, in retrospect, succeeds in maintaining the organism-environment fit then what one did was better than if along the way coordination faltered, and one failed to maintain this fit. Given this perspective on specification that is both processual and pragmatic, we do not need to think of normativity in terms of ambient patterns and correspondences. Nor do we need to think of correspondence, lawful or conventional, as specifying success conditions to different degrees prior to activity. Specification, as we already noted above, is not the source of situated activity but is the unfolding outcome of such activity.

While we deny that specification and information exists prior to an animal's activity, this does not amount to a denial of the reality of the meaningfully structured environment. By prioritizing world-involving activity, the usage-based account of information emphasizes that we are always already engaged with an open-ended meaningful world. We live and breathe in a material world that offers us endless possibilities for action. But perception, on our view, is not merely of reality, it is in reality. The animal perceives in the unfolding relations that Gibson called "affordances" (1979, p. 127), and it 
is in this unfolding relation that the organism and environment form. Affordances get specified in doing. Specification of affordances is not something lawfully structured energetic arrays can do on their own. It is in the context of the history of unfolding relations that patterns of correspondence are maintained and that newly achieved ambient patterns in the sea of energy get their informational significance.

We began this section by asking what the role of information is in perception given that there is no medium to contain information prior to action. We have seen how the role of information is in the end not different from the role it plays in orthodox ecological psychology. On our view, we can still think of ambient patterns as necessary for perception and action. We can also agree with the orthodox view in ecological psychology that, in the context of an ongoing information-relation, perception involves specification of the organism-environment relation-there is no non-specificity in our account. We can retain all these elements without thinking of information as the source of activity but instead thinking of the information-relation as forming in the process of specification. The advantage of our radical empiricist proposal, as we shall see in Sect. 5, is that it allow for an expanded ecological psychology that foregrounds the social nature of human experience. First however we must put our account to work to show how to understand direct perception given this usage based account of information.

\section{Direct perception in action}

What stands fast does so, not because it is intrinsically obvious or convincing; it is rather held fast by what lies around it. (Wittgenstein 1969, §144)

Our radical empiricist theory of direct perception begins from the unfolding organism-environment relation taking shape in action. It is in the midst of ongoing activity that the situation an animal directly perceives is disambiguated, and takes on a determinate character. It is in action that both the medium through which animals move and useful ambient patterns take shape. Differentiating a medium for action allows an organism to make use of ambient patterns of energy as their surrounds get specified. On this view direct perception happens in the process of specifying-in achieving useful patterns that maintain an information-relation across the organismenvironment system. The question we will answer in this section is how this relation is achieved.

\subsection{Perception as a skilled achievement}

On the activity-related view of the medium, useful patterns are brought about as the organism achieves and maintains coordination in its transactions with the environment. Figure 1 depicts the key concepts as we have developed them in their various relationships.

Specification, as we argued above and can been seen from Fig. 1, is an outcome that takes form over the course of ongoing situated activity. Perceiving is the process of achieving an information-relation. In this ongoing process, the active animal 


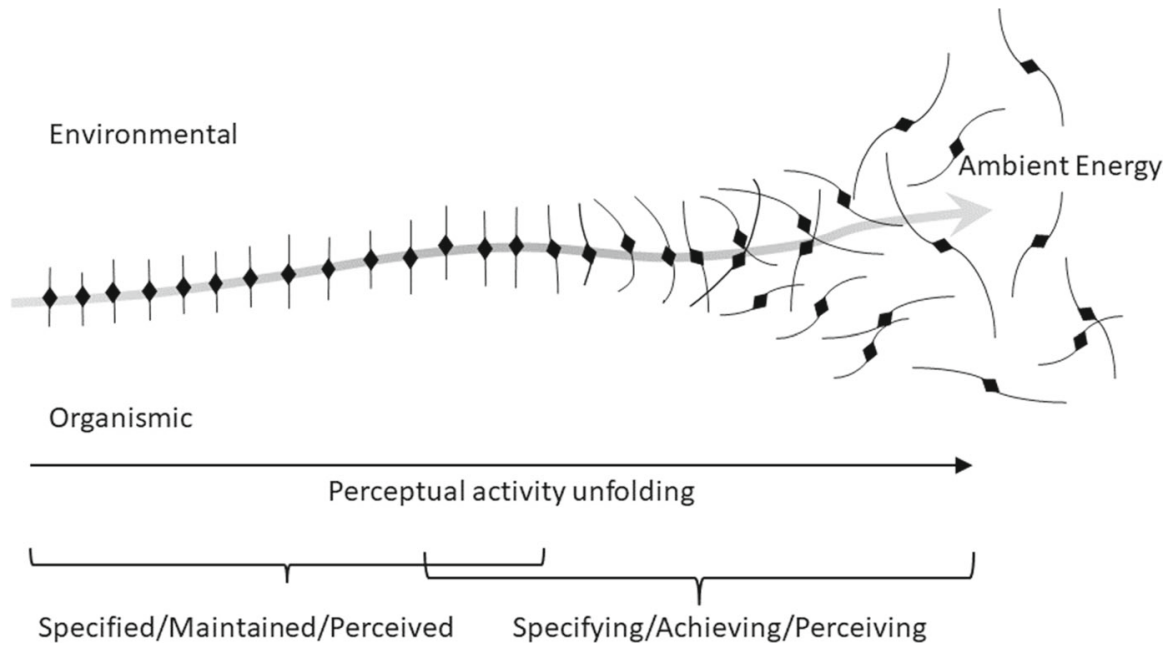

Fig. 1 Perceptual activity as an information-relation taking shape. This figure visualizes some of the key relations among the concepts as we introduce them. The small lines with a diamond shape in the middle represent ambient patterning (Sects. 2 and 3.1). Such patterns have their use relative to the overarching activity. In this activity over time the ambient pattern is achieved and maintained (represented by the black lines aligning and "straightening out"). Thus in the coordination of organism and environment correspondences between surfaces and ambient patterns become discernible. The medium is depicted inside not outside the unfolding action. It is indicated by the width of black lines aligned in activity. The black lines on the left-side of the figure depict the history of maintained coordination of organism and environment. The lines on the right-side are not yet aligned, indicating that coordination still needs to be achieved (Sect. 4.1). The richly patterned ambient energy (right-side of the figure) gets entangled in the medium of activity to give shape to a temporally extensive organismic process (lower-left part of the figure). The environmental aspects of the process (including surfaces and substances) are taking shape towards the upper-left part of the figure (as the black lines straighten out).The organism-environment fit thus increasingly takes shape historically, towards the left side of the figure. In activity the use of ambient patterns forms a (open-ended) path: an information-relation taking shape (Sect. 3.1). This information-relation is depicted by the grey arrow. The information-relation thus develops in action over time (drawn from left to right). Any ambient pattern (single black line) may be necessary for that relation to continue but is thus not sufficient (Sect. 3). Specification, and thus direct perception, happens in the activity of achieving and maintaining of coordination over time (Sect. 4). Note that if activity unfolds within the context of shared practices (see Sect. 5.1), such practices would pre-structure the environment. That might be shown by pre-orienting some of the lines to the right-hand side but is omitted in this figure

explores for and uses the patterning available in the ambient array so as to establish an information-relation. The animal achieves coordination by using ambient patterns in the activities of "listening, touching, smelling, tasting and looking" (Gibson 1966, p. 49, emphasis original). To make all of this more concrete, let us revisit our earlier example of swimming. We saw earlier how it is relative to activity that an organism is able to maintain water as a medium. Skillful coordination allows water to become a medium through which the swimmer can move. Moreover, making use of ambient light that reverberates throughout the water a skilled swimmer can see the fish that swim below the surface. Seeing the fish is enabled by the reverberating light in the water but only given the swimmer's ongoing skilled adjustments to the water's current as they meet resistance against their body. 
We can distinguish two interrelated aspects in the skills that are required for coordination of the type seen in the swimming example. First, there is an animal's history of practical engagement with water. For example, there are the skills the person develops in learning how to swim, which includes making the coordinative adjustments of their limbs to the water. These skills also include the movements of the "eye-head" system as the swimmer learns to adjust to conditions of seeing under water (Gibson 1966, p. 49). Second, skills form a history of prior activity, but this history is continued by the swimmer as they coordinate with their surrounds.

These two aspects, the maintained history of prior world-involving activity and the way the activity is achieved in its current unfolding, are reciprocally related in an ongoing process of perceiving. The way the organism and its environment have been coordinated in the past, the information-relation that has already been established, enables continuing the information-relation into the current situation. Conversely, by achieving coordination with ambient patterns anew, skilled perception is continued, and the possibility of establishing an information-relation is actively maintained. In short, we can think of the relation between the history of relevant activity and the way that this history is currently continued as open-ended yet diachronically constitutive of each other.

In maintaining an organism-environment fit (depicted on the left-hand side of Fig. 1), skilled activity continuously leads to a series of refined coordinative adjustments of the sensing body to its surrounds. These coordinative adjustments (towards the right-hand side of Fig. 1) achieve information-relations by exploring for patterns of ambient energy useful in the current situation. These adjustments establish the use of ambient patterns in activities of "listening, touching, smelling, tasting and looking." For example, maintaining an organism-environment fit by skillfully swimming allows adjustments of the eyes and head to achieve an information-relation by using (lawful) patterns in ambient light to follow the fish and see it swim by. Reciprocally, these achieved patterns continue the history of activity, and maintain the skill of swimming, which can enable specification anew. Thus, specification is achieved in making these continuous adjustments of the body to its surrounds. Such specification in action is the process of perceiving. Thus perception happens continuously as specification is achieved in action.

The radical empiricist thinks of perception as a historical and open-ended process. This allows ecological psychology to make headway in finding a place for social life in human perception (Costall 1995; Heft 2007). To account for the place of social life in perception we will suggest in the next section thinking of sociomaterial practices as integral to the medium, a possibility that opens up once we think of the medium in activity related terms. In Sect. 6 we return to the account of direct perception we have just sketched and show how to expand it to accommodate sociomaterial aspects of human engagement.

\section{Expanding the scope of ecological psychology}

The conception of the medium as ready-made has made it difficult for ecological psychologists to find a place for the open-ended sociomaterial dimensions of the human 
ecological niche. Ecological psychologists have struggled to make sense of how the social dimension of the environment could be "specified" in the ambient array (see Heft 2007; Chemero 2009 for discussion). On our account it is not necessary to have everything we act along with, such as social practices, be specified by (lawful) patterns of correspondence in advance of action. Patterns of practices need not map onto structured arrays of ambient energy contained in a medium. It is in the context of use that ambient patterns, lawful or otherwise, get their informational significance-not the other way around. Thus our radical empiricist account of direct perception opens the way to a more expansive ecological psychology that is able to accommodate social life. ${ }^{3}$

If we think of sociomaterial practices as informationally available (specified or not), this would assume that such practices, like other substances, are available in the environment to be perceived. On the radical empiricist view we are developing we will suggest to instead think of sociomaterial practices as the medium in which human (perceptual) activities unfold. Practices may be part of the perceptual process, but they are themselves not perceived. Just like air when walking or water when swimming underwater, we do not perceive the medium but, as we act, we perceive in the medium (Ingold 2011). Sociomaterial practices then do not need to be perceived in order for us to go along with them. We may for instance experience unreflectively what the appropriate way to act is when we enter a behavior setting such as a library or pharmacy (Heft 2007; Rietveld 2008). We can also be sensitive to the canonical use of familiar objects (Costall 1997) and thus perceive a hammer for what it affords, without needing to perceive the constellation of practices to which the hammer belongs. Such phenomena can be understood, as we will argue, as the experience of acting along with the medium of practice.

\subsection{Submitting to the medium of practices}

The spear suggests the feast not directly but through the medium of other external things, such as the game and the hunt, to which the sight of the weapon transports imagination (John Dewey 1958, p. 123)

Humans engage with what are often spatially remote aspects of the environment through the materials they find around them. When, for example, we're using a pen for writing on paper, when moving a wooden beam by carrying it together (Richardson et al. 2007) or when travelling by car and following the rules of the road to get to the other side of town, we "join forces" with materials and with other people (Ingold 2013, p. 31). In such cases the "substances" (the pen, the beam, other people, cars and road signs) do not merely resist deformation, but they enable one to engage an affordance that is only available given our participation in these ways of using materials and being involved with other people. Such activities incorporate, and span across, materials and other people redrawing their boundaries.

\footnotetext{
3 Others have aimed for a similar outcome by amending the orthodox notion of information with a less restrictive conception that ties ecological information to statistical regularities in the environment (Chemero 2009; Bruineberg et al. 2018). These statistical regularities would then constitute non-specifying information. We've argued above that the distinction between specifying and non-specifying information is not needed on a usage-based account.
} 
Consider the everyday activity of keeping an early morning appointment. The activities required to realize this possibility consist in, among other things, setting an alarm clock, getting up, making your way through traffic and knocking at the door of the office at the right time. In these actions the material substances and medium can be easily discerned. There is the alarm clock for instance that is set so as to enable us to wake in time to shower, take breakfast and to leave the house in time to beat traffic. There is the air surrounding the alarm clock that permits the unhindered movement of hitting it to end the annoyance of its ringing (which can reach us because air also retains ambient sound patterning). As we act however, stopping the alarm clock from ringing, travelling to work and arriving on time for our appointment, we also show attunement to and join in larger (societal) dynamics: getting up along with everybody else, using traffic signs as one does, and knocking on the door rather than just barging in. We participate in regular ways of doing things constitutive of a practice (Rietveld and Kiverstein 2014; Van Dijk and Rietveld 2018).

By participating in such practices, we do not merely encounter the resistance of clocks, cars and doors, as "substances," but we are also able to act with them. Alarm clocks, traffic systems, and buildings are all a part of the medium that enables the activity of making and keeping our appointment. We aim to work along with the resistance of these materials, acting with them (e.g. the alarm clock) to coordinate our activities to more remote and distal aspects of the environment - the time and place of our appointment. To paraphrase the quote from Dewey that forms the epigraph to this section, the alarm clock suggests getting out of bed through the medium of people and things, such as eating breakfast, keeping a work appointment, to which the sound of the alarm extends our activities. We engage affordances in this medium of people and things.

Consider what happens when we fail to coordinate appropriately to previously established practices. For example, when we set the alarm clock to snooze, oversleep and arrive too late for our appointment, or when we suddenly notice we are no longer driving along with the car next to us but see it moving dangerously close towards us, or when we barge into the office of a colleague rather than politely knocking and waiting at the door to be beckoned in. In various ways all these cases show faltering coordination, disattunement, to the regular ways of doing things. When this happens, one starts coordinating less to the spatially and temporally extensive affordance of making the appointment, but is immediately drawn to dealing with an affordance now much more pressing (Heft 2011; see Sect. 6.1). This may mean dealing with the angry frowns of colleagues, or rapidly steering away from the other car that is dangerously veering towards one.

In these cases, the materials and people one was acting along with suddenly offer resistance. Recall how water was enacted as a medium when coordinating skillfully but (re)turned to being a dangerous substance when coordination failed. Along the same lines, sociomaterial practices can likewise solidify into substance. When we find ourselves failing to join forces with the people and materials but instead working against them, they transform from a medium, which allows us to fluidly join forces with them, to a substance, offering resistance to our attempts at doing so. When this happens and coordination is not re-established, one risks drowning not in water but in an engulfing web of social or material threats. 
How do individuals act along the medium of practices? One might think that in order to take part in practices there needs to be information available to perceptual systems that specifies what to do. We've argued such a line of thinking is mistaken. Attunement to the medium of practice is cheap: one only needs to act in the flow of the larger scale dynamics, by achieving coordination to a particular situation. The individual thereby takes part in a shared history of practical engagement, and contributes to maintaining these large scale dynamics. In habitually getting up at the appropriate time by setting an alarm, one coordinates to, and contributes to maintaining societal (economic) patterns. By lining up in a queue at the pharmacy one adheres and contributes to the continuation of the practice of this behavior setting (Heft 2007). As we act along with these practices, the larger scale dynamic we take part in is not passively imposed on us, but is actively constituted in the very activity of adjusting for better or worse to the particular situation.

In order to maintain coordination to shared practices, other participants in the practice may point us to the way we (ought to) do things to get back on track when coordination falters. An angry frown or an appropriately placed gesture might show us that what we are doing is somehow out of step with wider practices, educating our attention to what the practice requires us to do. Corrections can also take an explicit linguistic form. Such linguistic activities can achieve and maintain explicit norms by articulating them, or writing them down as rules. Over time, doing so can change the possibilities for acting in that practice by the enforcing of norms (Noë 2015). Normative criteria are thus a particular way to continue and maintain a practice that people participate in together. 4

The medium people act in is a shared medium of sociomaterial practices unfolding out in the open. The medium of practice, because it belongs to a shared way of doing things, persists over a longer period of time than each of the individual actions of adjusting to it. The shared environment and the individual's skilled activities are reciprocally related and do not come ready-made. But neither need they be created anew with each individual action (James 1912, pp. 41-42; Costall 1997). Rather the activities of an individual developed in the medium of practice continues and refines the shared environment, while it in turn enables further activity to do so. The shared environment thus persists across individual adjustments to it, pre-structuring the environment for others learning to find their way. By participating in the medium of practice, we play our part in holding open a space for experiencing a shared world, a "clearing" (Heidegger 1962 ) in and along which we can act and perceive (with) others.

The expanded view of the medium we've developed in this section allows us to do justice to one of Gibson's reasons for introducing the medium in the first place.

\footnotetext{
4 One might think that once one makes a norm explicit either by discussing it or by writing it down, one thereby makes an issue of truth or correctness. There is now a question about the way the world is taken to be, where the world could be different from how it is taken to be. "Content" is thus in play. In our view, content, like any norm, is achieved and maintained by acting along a medium of practice. Consider for instance a train timetable. One might think that leaving at a certain time to catch a train implies a sensitivity to the correctness of the time table-acting in practical agreement with the timetable contributes to maintaining its correctness conditions. One may also say that it is only when the correctness or incorrectness of the timetable is discussed that any content is involved. We may even think of content as only belonging to highly institutionalized practices encountered chiefly at dedicated conferences and university departments where the existence of content is debated. Content does not travel between practices nearly as well as truth does (see Van Dijk and Myin 2018, p. 21).
} 
Gibson had the ambition to account for how animals are able to see and act in one and the same shared world. One way of doing that is to somehow make information intrinsically meaningful through lawful correspondences and thereby allow any animal picking up the same information to access the same world. This notion of information can then be expanded by including statistical regularities "about" the sociocultural environment (e.g. Bruineberg et al. 2018). In this section we've however explored a different possibility that follows from our usage-based account of information. We've shown how participation in sociomaterial practices can be enabling of the unfolding information-relation in which some ambient patterns are of shared use.

It is in the pragmatic relations one maintains that the shared environment gets to be perceived. Our view does not imply practices need to be perceived, let alone lawfully specified. Acting in the medium of practices, one can also learn to educate attention to ambient patterns that remain relatively invariant across a range of changing perspectives or circumstances. Our radical empiricist reading then again suggests a reversal. Instead of an animal gaining access to a shared world through lawful correspondences that specify such a world, it is because of a practically shared world that lawful correspondences have significance for all that learn to use them.

\section{Direct perception in context}

What strikes us first is this different pace of its parts. Like a bird's life, it seems to be made of an alternation of flights and perchings. (James 1890, p. 236)

In the radical empiricist account of direct perception we have developed in this paper, specification is achieved in the process of the animal exploring for and coordinating with the patterning available in the ambient array so as to achieve an information-relation. In the previous section we added the sociomaterial context in which this process of specification for a typical human animal unfolds. We are now in a position to make good on our promise to provide an account of direct perception as an activity humans achieve in the wider context of social life. In this section, we put the radical empiricist account of direct perception and the medium of practice together and deliver an account of direct perception in its sociomaterial context. We argue that while human organisms act along in the medium of practice, their historical and situated activities help to maintain coordination that continuously ends in a process of specification-of perceiving in context.

\subsection{Specification in the midst of social engagement}

As we attune to sociomaterial practices in our everyday doing, setting an alarm clock or keeping an appointment, we are sensitive to possibilities for action unfolding over extended spatial and temporal scales. We can anticipate what we will need to do to ensure we catch a train that departs at 3.30 later in the day, and coordinate our activities accordingly. An architect may anticipate that he will be able to make an architectural installation in a year from now. This anticipation, it was argued recently, is an experiential aspect of participating in determining a large-scale affordance (e.g. a 
train departing later in the day, an architectural installation that has not yet been built) as it unfolds across a multitude of activities (see Van Dijk and Rietveld 2018 for details on this large-scale notion of affordances). In both cases what a person anticipates is still indeterminate and not yet specified. It is a spatially and temporally extensive affordance that is set-up and maintained in the medium of practice.

Recall our view of the perceptual process (Fig. 1): in maintaining an organismenvironment fit skilled activity continuously leads to a series of refined coordinative adjustments of the sensing body to its surrounds, thus continuously achieving specification in action. As an individual engages an extensive affordance, it too can become more determinate in the course of their activity and can be specified or perceived as it gets determined over time. Contrast the architect that anticipates being able to make an installation and the architect that is standing in such an installation, seeing or touching it once it has been built and walking through it. Contrast anticipating catching the train and seeing the possibility to catch the train as you stand on the platform and the doors are opening in front of you (Hamlyn 1977; Noble 1981). The early experience of this affordance as it is still indeterminate and unfolding in the medium of practice differs significantly from the perceiving in affordances in their later, determinate, and now actively specified, form.

The difference, in our view, lies in the adjustments the perceiver makes in further specifying the possibilities for action present to her. Activities that contribute to keeping large scale possibilities for action available in the medium, such as catching a train, usually call for elaborate and temporally extensive activities. One for example needs to walk or bike to the station to catch the train. Maintaining such possibilities can be done in a multitude of different ways. The pace of walking and the route one takes contributes to some extent to maintaining the possibility of catching the train. That is, coordinating activities to maintain this possibility will require extensive dynamics of (whole body) activity and often allow for large variations in performance. As the relation to the train unfolds and gets a more specific shape, however, the adjustments made to maintain coordination become more fine-grained, and the details of the movement come increasingly to matter.

The activity required for catching the train and the actual jumping into the train converge on the same adjustments. Think of the activity of coordinating one's movements to the doors as one enters the train, for example, or touching the materials of an architectural installation one is standing in. This requires refined bodily adjustments by skillfully coordinating for example "eye-head" or "hand-body" systems with the environment (Gibson 1966, p. 49). At this point in engaging the affordance of catching a train, the activities that help determine the affordance converge on a series of coordinative adjustments that specify the affordance in action. This final determining in action is achieved by coordinating with useful ambient patterns of energy that establishes an information-relation (as discussed in Sect. 4). The information-relation for large scale affordances is again achieved by the activities of "listening, touching, smelling, tasting and looking" (ibid, emphasis original). Acting along affordances available in the medium of practice, continuously ends in a process of perceiving.

Skilled engagement with the environment consists of a multitude of such unfolding activities across time scales, which are coordinated relative to one another concurrently. As one activity nears completion, it will end with the refined bodily adjustments to 
the world through useful ambient patterns surrounding the perceiver. Through bodily adjustments, and the movement of their eyes, head and body for example, the perceiver is achieving ambient patterns that are immediately available for action. In this information-relation the perceiver is achieving contact with whatever is being heard, touched, smelled, tasted or looked at. All the while other skillful activities are directed towards spatially and temporally remote possibilities such as the architectural installation that is to be built, or the train that is to be caught sometime in the future. The ambient patterns necessary for the perception of these possibilities still remain indeterminate (unspecified), practically remote, and perhaps beyond our abilities to control.

\subsection{Absence in practice}

It might be objected that a perceiver can only have contact with an affordance when there is information available that specifies that affordance. But what is the information the environment makes available for perceiving the possibility to build an architectural installation, or to catch a train? We've been arguing that extensive affordances need not be perceived but that, in our coordination, they are presently part of the perceptual process. We argued the environment is not ready-made and does not come specified once-and-for-all. In an unfolding process, affordances are not momentarily absent or present in a physical (spatial or temporal) sense. Requiring specifying information about an affordance that is not sensibly present commits one to a representational role for information: that of standing in for something that is absent (e.g. Golonka and Wilson 2019). On our view, absence and presence are not fixed physical boundaries that determine the reach of direct perception, rather they are pragmatic features that take shape in the process of direct perception in its sociomaterial context.

In grabbing hold of her coat and quickening her step with the aim of catching a train, a person might experience the possibility to catch the train as outside of her practical grasp. She may experience how little her activities change anything in relation to the possibility to catch the train. Still, the fabric of the coat, the resistance of the ground while walking all are specified continuously in action, they have perceptual presence while the train does not. Yet in this unfolding action the possibility to catch the train is present in its absence. It is through the engagement with materials, attuned to the medium of practices, that the person is able to act so as to keep the possibility available, determine the possibility to catch the train further, and finally bring it to specification (cf. James 1912, p. 27 ff.). Perception, being processual and pragmatic, is thus always of what is present but it unfolds against a background in which a good deal of what we are dealing with is present only in its absence (Noë 2012).

On the other end of the spectrum, consider perceiving the stars, the sky or the sunset. The orthodox account of direct perception in ecological psychology requires specification through the relations among medium, substance and surface. In the absence of surfaced substances specified in a medium, perceiving the sky or the sunset seems impossible (Ingold 2011, p. 129). Moreover, light itself is, on this view, "unperceivable" (Turvey 2019, p. 371; p. 170; see Gibson 1979, p. 54). If light were perceived, so the argument goes, one would perceive the substances to which the light corresponds 
only indirectly. We however do perceive the sky, which lacks surfaces altogether. Perceiving the sky is an experience of light (Ingold 2011).

In looking up at the sky or gazing upon a sunset, one experiences absence in presence. The sky envelops us in light-it is an experience of light. In gazing at the sky, the sunrise or the stars, we may experience how little we can affect what we see. The stars or the sunset will not allow us to affect it-we cannot differentiate them from the medium of activity as substances that will resist our movement, for example. They afford very little. Unlike our relation to the train that we try to catch, our relation to the stars is unresponsive to any of our activities. There is no way to visit them. In fact they'll be there long after we die. Although the possibilities they offer may be slightly better for those who can name the signs or for an astronomer who might be familiar with practices of measuring a star's distance in parsecs, perceiving the twinkling of the stars or the blueness of the sky can be an overwhelming experience of our own insignificance in relation to it. In gazing at the stars or looking for the big dipper and naming it, skillfully tuning one's eyes and head to the lights in the heaven, one experiences the inability of any way to achieve a practical relation to the stars beyond seeing and naming them.

Our account answers a related question raised in criticism of Gibson, early in the articulation of his theory of direct perception. David Hamlyn pointed out that the same information is available to each of the perceptual systems, and thus the notion of information seems unable to account for the distinctively visual experience when we see a bottle fill up as contrasted with the auditory or haptic experience when we hear the bottle being filled or feel its weight increasing in our hand (Hamlyn 1977). On our account, these visceral and sensuous features of perception are achievements of a skilled organism that, situated in the medium of practice, has learned to differentiate its environment. In the course of development, one can learn that different aspects of the body are differentially sensitive to the environment. An organism, especially once steeped in sociomaterial practices such as language, can learn to make the activity of perceiving an issue for itself: "when adopting a self-conscious attitude, we can attend to the fact that we can attend to the world with our hands separately from our eyes" (Noble 1981, p. 69). By developing in the course of situated doing, perceiving in light, in sound, and in sociomaterial practices, one can not only engage the environment at large, but one can experience the body as that which one perceives from (ibid.).

\section{Concluding remarks}

In order to account for direct perception in ways consistent with radical empiricism we've developed the notion of 'medium' in ecological psychology. We argued that Gibson used the concept of the medium in two incompatible ways. We've shown how the activity-related view of the medium allows for a view of direct perception consistent with Gibson's radical empiricist roots. Radical empiricism described organisms as experiencing the relation they maintain with their surroundings prior to any analytic separation of the organism from its (shared) environment. We've provided an ecological elaboration of radical empiricism by showing how to understand the key ecological notions of medium, ambient energy and information in the wider context of ongoing 
human activity. Information is not a ready-made quantity carried in the medium. It is by actively maintaining coordination with ambient patterns that active perceivers establish an information-relation to their surrounds. The activity-related view of the medium, and the usage-based account of information it implies finally allowed us to expand the human-environment to include sociomaterial practices. Practices form a medium of perception for humans. It is in practices that the use of ambient patterns is achieved. Thus, we arrived at an account of direct perception as it unfolds in social life. Co-becoming with a shared environment organisms are in direct contact with their surrounds-perception serves to keep them that way.

Acknowledgements We thank Rob Withagen for his commenting on an earlier version of this paper. We are also grateful to two anonymous reviewers for their insightful suggestions. Julian Kiverstein's work was supported by the European Research Council (ERC Starting Grant, 679190 awarded to Erik Rietveld for the project Affords-Higher). The research of Ludger van Dijk was supported by the Research Foundation Flanders (FWO project 'Thinking in practice: a unified ecological-enactive account,' 12V2318N).

Open Access This article is licensed under a Creative Commons Attribution 4.0 International License, which permits use, sharing, adaptation, distribution and reproduction in any medium or format, as long as you give appropriate credit to the original author(s) and the source, provide a link to the Creative Commons licence, and indicate if changes were made. The images or other third party material in this article are included in the article's Creative Commons licence, unless indicated otherwise in a credit line to the material. If material is not included in the article's Creative Commons licence and your intended use is not permitted by statutory regulation or exceeds the permitted use, you will need to obtain permission directly from the copyright holder. To view a copy of this licence, visit http://creativecommons.org/licenses/by/4.0/.

\section{References}

Baggs, E., \& Chemero, A. (2018). Radical embodiment in two directions. Synthese. https://doi.org/10.1007/ s11229-018-02020-9.

Bateson, G. (1972). Step to an ecology of mind. Chicago, IL: University of Chicago Press.

Bruineberg, J., Chemero, A., \& Rietveld, E. (2018). General ecological information supports engagement with affordances for higher cognition. Synthese, 196, 1-21.

Chemero, A. (2009). Radical embodied cognitive science. Cambridge, MT: The MIT Press.

Costall, A. (1984). Are theories of perception necessary? Journal of the Experimental Analysis of Behavior, 41(1), 109-115.

Costall, A. (1995). Socializing affordances. Theory \& Psychology, 5(4), 467-481. https://doi.org/10.1177/ 0959354395054001.

Costall, A. (1997). The meaning of things. Social Analysis, 41(1), 76-85.

Costall, A., \& Still, A. (1989). Gibson's theory of direct perception and the problem of cultural relativism. Journal for the Theory of Social Behaviour, 19, 433-441.

Dewey, J. (1958). Experience and nature. New York, NY: Dover Publications.

Gibson, J. J. (1950). The perception of the visual world. Boston, MT: Houghton, Mifflin and Company.

Gibson, J. J. (1966). The senses considered as perceptual systems. Boston, MT: Houghton, Mifflin and Company.

Gibson, J. J. (1967). Autobiography. In E. G. Boring \& G. Linzey (Eds.), A history of psychology in autobiography (Vol. 5, pp. 127-143). New York, NY: Appleton-Century-Crofts.

Gibson, J. J. (1979). The ecological approach to visual perception. Boston, MT: Houghton, Mifflin and Company.

Golonka, S., \& Wilson, A. (2019). Ecological representations. Ecological Psychology, 31(3), $235-253$. https://doi.org/10.1080/10407413.2019.1615224.

Hamlyn, D. W. (1977). The concept of information in Gibson's theory of perception. Journal for the Theory of Social Behaviour, 7(1), 5-16. https://doi.org/10.1111/j.1468-5914.1977.tb00374.x. 
Heft, H. (1989). Affordances and the body: An intentional analysis of Gibson's ecological approach to visual perception. Journal for the Theory of Social Behaviour., 19, 1-30.

Heft, H. (2001). Ecological psychology in context: James Gibson, Roger Barker, and the legacy of William James's radical empiricism. Mahwah, NJ: Lawrence Erlbaum Associates.

Heft, H. (2007). The social constitution of perceiver-environment reciprocity. Ecological Psychology, 19(2), $85-105$.

Heft, H. (2011). Holt's "Recession of the Stimulus" and the emergence of the "Situation" in psychology. In E. P. Charles (Ed.), A new look at new realism: the psychology and philosophy of E.B. Holt (pp. 191-219). New Brunswick, NJ: Transaction Publishers.

Heft, H. (2017). William James' psychology, radical empiricism, and field theory: Recent developments. Philosophical Inquiries, 5, 1-29.

Heidegger, M. (1962). Being and time (J. Macquarrie \& E. Robinson, Trans.). New York, NY: Harper and Row.

Heider, F. (1959). Thing and medium. Psychological Issues, 1(3), 1-34.

Heras-Escribano, M. (2019). Pragmatism, enactivism, and ecological psychology: towards a unified approach to post-cognitivism. Synthese. https://doi.org/10.1007/s11229-019-02111-1.

Hutto, D. D., \& Myin, E. (2013). Radicalizing enactivism: Basic minds without content. Cambridge, MT: MIT Press.

Ingold, T. (2011). Being alive: Essays on movement, knowledge and description. Abingdon, UK: Routledge.

Ingold, T. (2013). Making: Anthropology, archeology, art and architecture. Abingdon, UK: Routledge.

James, W. (1890). The principles of psychology. New York, NY: Dover Publications.

James, W. (1912). Essays in radical empiricism. Mineola, NY: Dover Publications Inc.

Johnston, T. (1997). Comment on cooper. In C. Dent-Read \& P. Zokow-Goldring (Eds.), Evolving explanations of development (pp. 87-89). Washington, DC: American Psychological Association.

Kiverstein, J., Van Dijk, L., \& Rietveld, E. (2019). The field and landscape of affordances: Koffka's two environments revisited. Synthese. https://doi.org/10.1007/s11229-019-02123-x.

Lee, D. N., \& Reddish, P. E. (1981). Plummeting gannets: a paradigm of ecological optics. Nature, 293, 293-294.

Mace, W. M. (2002). The primacy of ecological realism. Behavioral and Brain Sciences, 25, 111. https:// doi.org/10.1017/S0140525X0237002X.

Michaels, C. F., \& Carello, C. (1981). Direct perception. Englewood Cliffs, NJ: Prentice-Hall Inc.

Noble, W. G. (1981). Gibsonian theory and the pragmatist perspective. Journal for the Theory of Social Behaviour, 11, 65-85. https://doi.org/10.1111/j.1468-5914.1981.tb00023.x.

Noë, A. (2012). Varieties of presence. Cambridge, MA: Harvard University Press.

Noë, A. (2015). Strange tools. New York, NY: Hill and Wang.

Oyama, S. (2000). The ontogeny of information: Developmental systems and evolution (2nd ed.). New York: Cambridge University Press.

Reed, E. S. (1988). James J. Gibson and the psychology of perception. New Haven, CT: Yale University Press.

Richardson, M. J., Marsh, K. L., \& Baron, R. M. (2007). Judging and actualizing intrapersonal and interpersonal affordances Journal of Experimental Psychology: Human Perception and Performance., 33(4), 845-859. https://doi.org/10.1037/0096-1523.33.4.845.

Rietveld, E. S. (2008). Situated normativity: The normative aspect of embodied cognition in unreflective action. Mind, 117(468), 973-1001. https://doi.org/10.1093/mind/fzn050.

Rietveld, E. S., \& Kiverstein, J. (2014). A rich landscape of affordances. Ecological Psychology, 26(4), 325-352. https://doi.org/10.1080/10407413.2014.958035.

Schatzki, T. (2012). A primer on practices. In J. Higgs, R. Barnett, S. Billett, M. Hutchings, \& F. Trede (Eds.), Practice-based education (pp. 13-26). Rotterdam: Sense Publishers.

Segundo-Ortin, M., Heras-Escribano, M., \& Raja, V. (2019). Ecological psychology is radical enough: A reply to radical enactivists. Philosophical Psychology, 32(7), 1001-1023. https://doi.org/10.1080/ 09515089.2019.1668238.

Shotter, J. (1983). "Duality of structure" and "intentionality" in an ecological psychology. Journal for the Theory of Social Behaviour., 13, 19-44. https://doi.org/10.1111/j.1468-5914.1983.tb00460.x.

Turvey, M. T. (1990). The challenge of a physical account of action: A personal view. In H. T. A. Whiting, O. G. Meijer, \& P. C. W. van Wieringen (Eds.), A natural-physical approach to movement control (pp. 57-93). Amsterdam: Free University Press. 
Turvey, M. T. (1992). Affordances and prospective control: An outline of the ontology. Ecological Psychology, 4(3), 173-187. https://doi.org/10.1207/s15326969eco0403_3.

Turvey, M. T. (2019). Lectures on perception: An ecological perspective. New York: Routledge.

Turvey, M. T., \& Shaw, R. E. (1999). Ecological foundations of cognition. I: Symmetry and specificity of animal-environment systems. Journal of Consciousness Studies, 6(11-12), 95-110.

Van Dijk, L. (2016). Laying down a path in talking. Philosophical Psychology, 29(7), 993-1003. https:// doi.org/10.1080/09515089.2016.1213379.

Van Dijk, L., \& Myin, E. (2018). Reasons for pragmatism: Affording epistemic contact in a shared environment. Phenomenology and the Cognitive Sciences. https://doi.org/10.1007/s11097-018-9595-6.

Van Dijk, L., \& Rietveld, E. (2018). Situated anticipation. Synthese. https://doi.org/10.1007/s11229-01802013-8.

Van Dijk, L., Withagen, R. G., \& Bongers, R. M. (2015). Information without content: A Gibsonian reply to enactivists' worries. Cognition, 134, 210-214. https://doi.org/10.1016/j.cognition.2014.10.012.

Vaz, D. (2015). Direct perception requires an animal-dependent concept of specificity and of information. Ecological Psychology, 27(2), 144-174. https://doi.org/10.1080/10407413.2015.1027128.

Warren, W. H., Kay, B. A., Zosh, W. D., Duchon, A. P., \& Sahuc, S. (2001). Optic flow is used to control human walking. Nature Neuroscience, 4(2), 213-216. https://doi.org/10.1038/84054.

Withagen, R., \& Chemero, A. (2009). Naturalizing perception developing the Gibsonian approach to perception along evolutionary lines. Theory \& Psychology, 19(3), 363-389. https://doi.org/10.1177/ 0959354309104159.

Withagen, R., \& van der Kamp, J. (2010). Towards a new ecological conception of perceptual information: Lessons from a developmental systems perspective. Human Movement Science, 29(1), 149-163. https://doi.org/10.1016/j.humov.2009.09.003.

Wittgenstein, L. (1969). On certainty (D. Paul \& G. E. M. Anscombe, Trans.). Oxford: Blackwell Publishing.

Publisher's Note Springer Nature remains neutral with regard to jurisdictional claims in published maps and institutional affiliations. 